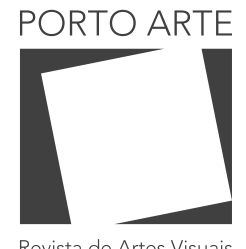

v. 25 ก. 43 Jan/jun 2020 e-ISSN: 2179-8001

\title{
Exposição colecionismo: relações entre curadoria e mercado da arte
}

Collecting exhibition: relationship between curatorship and the art market

\section{Rittieli D'Avila Quaiatto}

ORCID: 0000-0002-8282-5166

Universidade Federal de Santa Maria, Brasil

\section{Andrea Capssa de Lima}

ORCID: 0000-0002-2416-7695

Universidade Federal de Santa Maria, Brasil

\section{Resumo}

Este artigo no campo da História, Teoria e Crítica da Arte contribui para pensar as relações entre a curadoria e o mercado da arte, com análise crítica de estratégias expositivas utilizadas em galerias de arte. Por meio dos conceitos e práticas curatoriais da exposição “Colecionismo", realizada em 2019, na qual obras de artistas expoentes da História da Arte convergem com produções contemporâneas de artistas representados pela galeria, compreende-se, no sistema da arte, as dinâmicas voltadas para o colecionismo e o investimento em arte, com base na legitimação e visibilidade.

Palavras-chave

Arte Contemporânea. Curadoria. Mercado da Arte. Colecionismo. Estratégia Expositiva.

\section{Abstract}

This article in the field of History, Theory and Criticism of Art contributes to think about the relationship between curatorship and the art market, with a critical analysis of exhibition strategies used in art galleries. Through the curatorial concepts and practices of the exhibition "Colecionismo", held in 2019, in which works by artists who are exponents of Art History converge with contemporary productions by artists represented by the gallery, in the art system, it is understood dynamics focused on collecting and investing in art, based on legitimation and visibility.

Keywords

Contemporary Art. Curatorship. Art Market. Collecting. Exhibition Strategy. 


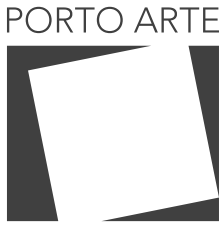

Revista de Artes Visuais

$\vee 25 \times 43$ Jan/jun 2020 e-ISSN: 2179-8001

\section{Mercado da arte: o colecionador e a arte como investimento}

Em agosto de 2019 constitui-se em Santa Maria/RS uma galeria de arte, após uma década de ausência de galerias na cidade, o que evidencia um dos grandes desafios enfrentados por seus agentes, pois torna-se imprescindível a formação de um público com ênfase ao circuito artístico local. Apesar de ser conhecida como "Cidade Cultura" e dispor de museus, teatro, cinemas e outros espaços culturais, percebe-se em Santa Maria um déficit de público em todos os locais de cunho artístico-cultural, talvez por necessitar de maiores investimentos, públicos e/ou privados, bem como de pluralidade de ações no âmbito das artes. Nesse cenário, evidentemente, por falta de hábito da população e, sobretudo, de incentivo à educação cultural, torna-se mais complexo o trabalho a fim de abrir mercado local para a arte.

De início, parece que, quanto mais olhamos, menos certeza podemos ter quanto àquilo que afinal, permite que as obras sejam qualificadas como 'arte', pelo menos de um ponto de vista tradicional. Por um lado, não parece haver mais nenhum material particular que desfrute do privilégio de ser imediatamente reconhecível como material da arte: a arte recente tem utilizado não apenas tinta, metal e pedra mas também ar, luz, som, palavras, pessoas, comida e muitas outras coisas. Hoje existem poucas técnicas e métodos de trabalho, se é que existem, que podem garantir ao objeto acabado a sua aceitação como arte. (ARCHER, 2001, p. IX).

O que se considera arte parte da classificação e de sua inserção em um sistema que diz respeito ao

[...] conjunto de indivíduos e instituições responsáveis pela produção, difusão e consumo de objetos e eventos, por eles mesmos rotulados como artísticos, e, também, pela definição dos padrões e limites da Arte para uma sociedade, ao longo de um período histórico. (BULHÕES, 1990, p. 17).

O mercado da arte é um dos grandes pilares do sistema da arte e corresponde ao setor econômico, em que as suas transformações e fluxos refletem o modo de atuação dos agentes em diversas esferas. As exposições de galerias têm como característica atrair e fidelizar clientes, conquistar colecionadores e alcançar êxito nas vendas de suas obras, tanto no mercado primário quanto no secundário. 


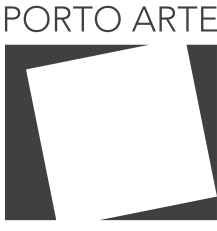

Revista de Artes Visuais

$\vee 25 n .43$

Jan/jun 2020 e-ISSN: 2179-8001

No mercado primário, a obra de arte entra em circulação diretamente do ateliê do artista, por meio das galerias, marchands, ou art dealers. A relação artista<> galeria ${ }^{1}$ <>colecionador configura a tríplice do mercado primário no sistema da arte. A obra de arte, quando vendida pela primeira vez, em que seu único proprietário até então tenha sido o próprio artista, é procedente do mercado primário.

0 mercado secundário consiste na revenda de obras de arte. Escritórios de arte, casas de leilões, marchands, dealers, ou galeristas que trabalham com revenda de obras recolocam no mercado da arte peças anteriormente comercializadas no mercado primário. A obra que já teve sua aquisição realizada por colecionador, seja coleção particular, privada, corporativa, ou institucional, e retorna por meio do dealer, marchand, galerista, ou leiloeiro, para o encontro de novo colecionador/investidor, é procedente do mercado secundário.

Diante do dinamismo do mercado, os agentes do mercado da arte buscam atrair novos colecionadores, na intenção de abrir mercado na sua pluralidade, e que vai ao encontro das características das galerias contemporâneas que optam por transformações e atualizações para construir bases de clientes (LINDEMANN, 2006). De acordo com Ana Letícia Fialho, "[...] no sentido mais abrangente, o mercado engloba obras de arte de diferentes períodos e estilos, inclusive antiguidades, e envolve agentes e empresas de perfil bastante diverso." (FIALHO, 2014, p. 37).

0 modelo de negócios praticado pode estar voltado para o mercado primário, ou secundário, ou ambos. $O$ alcance pode ser local, regional ou internacional e vai ao encontro das dinâmicas estabelecidas pelos agentes no campo da arte, bem como as tipologias dos objetos negociados, estilos, períodos, que podem ser diversos, tais como arte moderna, contemporânea, ou ainda antiguidades, para citar exemplos. A galeria santa-mariense, Moblanc, atua no mercado primário e no mercado secundário, concomitantemente, e tem como propósito a formação cultural do público visitante. É importante, sobretudo para a curadoria, definir o público-alvo da galeria para a definição de conceitos para exposições, porém é possível estender as ações para além da venda, com vistas ao fomento e ao acesso do público à cultura.

Segundo Maria Amélia Bulhões (2019), a arte contemporânea no Brasil é inserida a partir de estratégias que visam a legitimação ao disponibilizar obras de maior circulação, como pinturas, esculturas e desenhos, juntamente às obras ousadas e menos mercadológicas, a fim de inovar como atrativos e constituir referências conceituais. Essa prática é vista com temor por alguns setores artísticos que compreendem a absorção pelo mercado como um esvaziamento de sua função crítica. Estratégias de marketing e o impulso ao investimento de ousadia (que aplica para o futuro e diz respeito à aquisição de obras de artistas desconhecidos) são destaques no mercado nacional e indicam a necessidade de assessoria aos novos e também aos experientes colecionadores.

1- Galeria como vendedora da arte, que pode ser substituída pela figura do art dealer, ou marchand, ou qualquer outro agente de mercado que atue enquanto "ponte" entre o artista e o comprador, que pode ser um colecionador. 


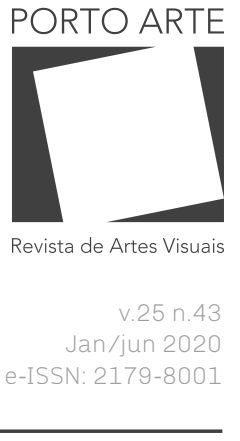

A atuação dos galeristas nas vanguardas da arte contemporânea passou a ser uma característica preponderante do meio de arte no Brasil, com crescente importância destas enquanto instância de legitimação, com decisivo papel na circulação dessa produção. Os colecionadores, tanto os mais tradicionais como também os mais jovens e ousados, recorrem a galeristas ou consultores como apoio especializado em suas escolhas. (BULHÕES, 2019, p. 50).

Bulhões (2019) afirma ser a articulação entre o mercado e as instituições, fundamental para garantir legitimidade ao circuito artístico, apesar de haver ainda certa resistência da parte de alguns agentes do sistema.

Ainda há muitos integrantes do meio artístico no Brasil (críticos, artistas, marchands, e diretores de instituições etc.) que resistem a qualquer análise do mercado, separando obstinadamente, em seus discursos, a arte de seu consumo. Esse tipo de atitude decorre de uma visão romântica que tenta negar a condição mercadológica dessa prática social no mundo capitalista. Entretanto, as funções exercidas pelo mercado no desenvolvimento da arte contemporânea no País colocam-no como uma das principais instâncias responsáveis pela circulação e pela legitimação dessa produção. (BULHÕES, 2019, p. 41).

Tratando-se de mercado da arte contemporânea, leva-se em conta o grau de incerteza que afeta tanto o valor estético quanto financeiro das obras (QUEMIN, 2014). Segundo Raymonde Moulin (2007), enquanto o segmento do mercado de arte antiga é amplo e estável, o segmento da arte contemporânea é considerado estreito e evolutivo. Quanto à legitimação da arte contemporânea, observa-se que parte da atuação dos principais agentes do sistema: diretores de grandes museus, curadores, críticos de arte, galeristas com relevante atuação, casas de leilão, grandes colecionadores e artistas midiáticos.

A constituição dos valores artísticos contemporâneos, no duplo sentido estético e financeiro do termo, efetua-se pela articulação do campo artístico e do mercado. 0 preço ratifica, com efeito, um trabalho não econômico de credibilização no plano estético, um trabaIho de homologação do valor realizado pelos especialistas, isto é, pelos críticos, historiadores da arte contemporânea, conservadores de museu, administradores da arte e curadores. Uma vez obtido no mercado, o preço facilita e acelera a circulação e a internacionalização do julgamento estético. (MOULIN, 2007, p. 26). 


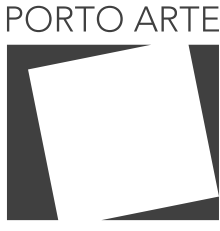

Revista de Artes Visuais

$\vee 25 n .43$

Jan/jun 2020 e-ISSN: 2179-8001

De acordo com Alexandre Melo (2012), a criação e a elaboração de processos de valorização das obras competem aos agentes culturais. Não há uma explicação estritamente econômica para a compra de obras de arte, pois essa ação exige motivação pessoal e cultural, bem como intuição e sensibilidade, para além dos aspectos econômicos. As conexões socioculturais estão imersas nessa relação de mercado. Há que se destacar, ainda, os objetivos possíveis para que as relações comerciais aconteçam nessa esfera e que correspondam ao longo prazo (reserva de valor), ao médio prazo (o investimento), ou ao curto prazo (a especulação).

O investimento a longo prazo diz respeito à aquisição de obras reconhecidas pela história da arte, predominantemente raras, possuem maior valoração e asseguram um investimento de baixo risco, ainda que sujeitas às flutuações e oscilações de preço que podem variar de acordo com a época. $O$ investimento a médio prazo comporta um grau de risco maior, com variações de gosto, movimentos estéticos, a moda e outras possíveis alterações. 0 investimento a curto prazo corresponde à lógica especulativa, à instabilidade do mercado com períodos de euforia e de recessão; obras de arte contemporânea, por exemplo, podem estar associadas a esse tipo de investimento, uma vez que entram no mercado como grandes apostas de galerias e exigem maior informação e intuição dos agentes.

Destaca-se aqui a figura do colecionador que, além da dimensão econômica, está diretamente vinculado à dimensão cultural - e que também corresponde ao sistema da arte. 0 colecionador compreende o prazer emocional ou intelectual intrínseco à operação de aquisição de obras de arte. Segundo Melo (2012), diz respeito ao investimento afetivo e intelectual, ao prazer estético e também ao prestígio social com foco na rentabilização de suas coleções, não somente monetárias, mas de prestígio social. 0 mercado da arte está, portanto, diretamente ligado aos processos de legitimação, visibilidade, prestígio social, informação e valoração da arte contemporânea.

Entretanto, observa-se que o grande público, a grosso modo, não costuma comprar obras de arte, por não ter condições financeiras, ou por desconhecer o caminho para tornar-se um colecionador, porém é ele que está mais presente nas exposições. Nesse sentido, a galeria e os demais agentes e instituições do sistema da arte, aliados às práticas curatoriais, devem buscar educar o seu público e lançar mão de ações que possibilitam a aquisição e a fruição das obras de maneira facilitada, por meio de condições de pagamento, valores acessíveis, ações esporádicas como leilões de parede, mediação cultural, disponibilização de materiais impressos ou em formato digital que auxiliem na reflexão sobre as exposições e visitas guiadas. Essas são algumas estratégias a serem desenvolvidas e ampliadas para formarem seus públicos.

O colecionismo enquanto motivação econômica vai além de números e cifras. São diversas as situações que levam uma pessoa a colecionar arte, podem-se observar casos privilegiados de acesso às obras de arte, de aspiração a um prestígio social, exibicionismo, noções de virtude cívica elevada, ou o prazer intelectual e emocional ao colecionar arte. Trata-se de um investimento acompanhado de diversas sensações e reflexões, diferentemente de um investimento em negócios imobiliários e automotivos, por exemplo, devido à sua dimensão cultural em que somente dinheiro não basta. 


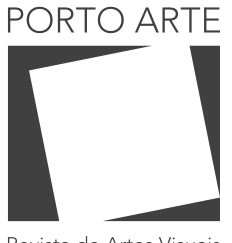

v. 25 n. 43 Jan/jun 2020 e-ISSN: 2179-8001
[...] uma lógica puramente econômica ou, em termos mais simplistas, a simples busca do lucro, não bastaria, por si só, para justificar o colecionismo e a existência e o funcionamento do mercado da arte. Antes de mais, porque há uma excessiva margem de risco e imprevisibilidade neste tipo de investimentos quando comparado com outros. (MELO, 2012, p. 12).

Alexandre Melo também destaca o papel dos agentes culturais como fundamental para incentivar o colecionismo, pois a informação e o conhecimento sobre arte é o ponto-chave mercadológico. "O modo de inserção da arte contemporânea na sociedade assenta numa estreita articulação entre a dimensão econômica e a dimensão cultural" (MELO, 2012, p. 14).

\section{Exposição "Colecionismo"}

Para a exposição de inauguração "Colecionismo", a curadoria reuniu uma vasta seleção de obras de arte em parceria com o colecionador Arnaldo Buss, diretor da Galeria Espaço Cultural Duque, de Porto Alegre, a fim de realizar uma exposição inédita na cidade de Santa Maria/RS, com obras de artistas renomados, em diversas técnicas, tais como pintura, escultura, gravura e desenho. Nesse projeto, foram incluídos artistas contemporâneos (e novas mídias), considerados pela curadoria como jovens e talentosos artistas que buscam, por meio de sua arte e de múltiplas linguagens e pesquisas, afirmar suas potencialidades no campo da pintura, gravura, desenho, escultura, fotografia, videoperformance e realidade aumentada.

A mostra buscou reunir obras raras e originais de expoentes da história da arte como Cândido Portinari, Di Cavalcanti, Antonio Bandeira, Pablo Picasso, Tarsila do Amaral, Iberê Camargo, entre outros ${ }^{2}$, e também artistas que produzem na contemporaneidade, representados pela própria galeria e pelo Escritório de Arte de Porto Alegre. A exposição procurou evidenciar em sua proposta uma mescla entre o moderno e o contemporâneo, a partir de uma estratégia de mercado amplamente utilizada por galerias comerciais, para legitimar artistas emergentes junto aos renomados. A exposição inaugural, "Colecionismo", recebeu visitação durante todo o mês de setembro de 2019, com uma dinâmica diferenciada, pois as obras, disponíveis para comercialização, eram substituídas por outras, do mesmo artista, série e/ou temática, na medida em que as peças vendidas eram encaminhadas aos seus novos proprietários.

\footnotetext{
2- Relação completa dos artistas da "Colecionismo" dividida em três acervos. Acervo da Galeria Duque, composto por obras de: Ado Malagoli, Aldemir Martins, Alexandre Rapoport, Alfredo Ceschiatti, Alice Brueggemann, Alice Soares, Anita Malfatti, Antonio Bandeira, Arcangelo Ianelli, Arthur Luiz Piza, Bruno Giorgi, Cândido Portinari, Carlos Scliar, Carlos Vergara, Carybé, Danúbio Gonçalves, Djanira da Motta e Silva Emiliano Di Cavalcanti, Henri de Toulouse-Lautrec, Iberê Camargo, Inos Corradin, João Luís Roth, Jorge Guinle, Leopoldo Gotuzzo, Manabu Mabe, Nelson Jungbluth, Oscar Crusius, Pablo Picasso, Paula Kadunc, Pedro Weingärtner, Roberto Burle Marx, Salvador Dalí, Tarsila do Amaral. Tomie Ohtake, Siron Franco, Vasco Prado, Vitório Gheno, Vik Muniz e Xico Stockinger. Acervo da Moblanc, composto por obras de: Carlos Donaduzzi, Carolina Berger, Catiuscia Dotto, Giovana Casimiro, Gustavo Freitas, Kelly Pfüller, Lutiere Dalla Valle e Walesca Timmen. Acervo do Escritório de Arte, por meio da obra do artista convidado: Juliano Lopes
} 


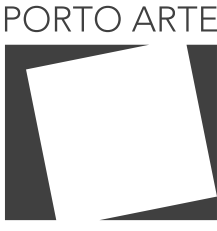

Revista de Artes Visuais

v. 25 ก. 43 Jan/jun 2020 e-ISSN: 2179-8001

Figura 1 - Folder "Colecionismo". Fonte: Acervo particular

O vernissage que marcou a abertura da galeria foi realizado exclusivamente para convidados no dia 21 de agosto de 2019. No dia seguinte, a exposição foi aberta para o público geral. Assim, as estratégias de comunicação foram divididas em três momentos: pré-inauguração, vernissage e pós-abertura.

Como estratégias de comunicação, optou-se por utilizar também as redes sociais ${ }^{3}$ Instagram e Facebook. Primeiramente, as postagens foram produzidas para instigar possíveis visitantes sobre o novo espaço de arte na cidade, gerar curiosidade e interesse e disseminar conteúdo.

Para o segundo momento, o vernissage foi desenvolvido um material para consulta sobre os artistas e as obras em exposição. Nesse material constava a imagem de cada obra ali exposta, o nome do artista e sua biografia, e a ficha técnica correspondente. 0 material, impresso em formato de livro, ficou disponível na exposição para que os visitantes o manipulassem, de acordo com suas necessidades e interesses, durante o vernissage e após a abertura, durante todo o mês em que a exposição esteve aberta ao público.

A curadoria também selecionou obras para constar no material físico de divulgação da mostra, por meio de folders impressos, para serem distribuídos durante o vernissage e após a abertura (Figura 1). Todo o trabalho de curadoria corroborou na produção do catálogo da exposição Colecionismo, que em breve será lançado.
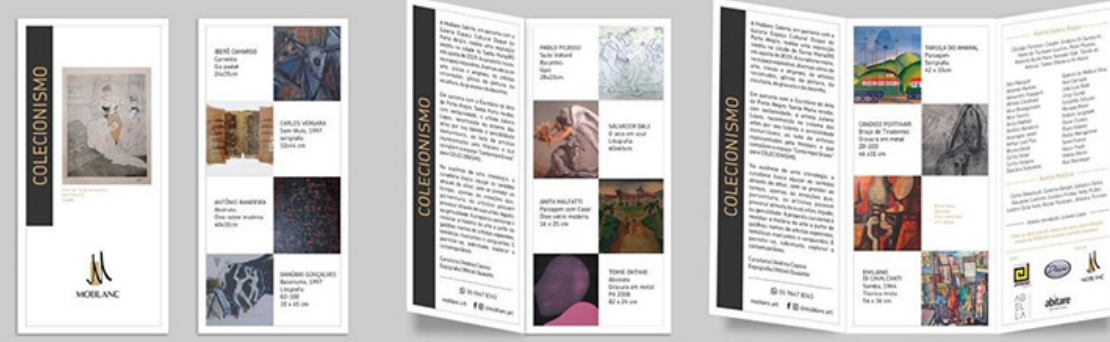

No primeiro dia da mostra, no vernissage, foram contabilizados cerca de 200 visitantes, que compareceram durante as quatro horas em que a exposição ficou aberta ao público. A exposição foi um grande evento para o meio cultural da cidade e por isso foi amplamente veiculada em diferentes mídias.

No terceiro momento, visando um maior acesso ao público, foram agendadas visitas guiadas, realizadas pelas curadoras, que também se encarregaram de recepcionar todos os visitantes durante o período da mostra. E, com intuito de alcançar públicos em potencial, realizou-se uma série de vídeos, nos quais são apresentados o contexto da mostra, alguns artistas e suas trajetórias e pequenos registros de percursos pelo espaço expositivo, a fim de também proporcionar certa experiência mesmo

3- Disponíveis em: <https://www.instagram.com/moblanc.art/>e

< https://www.facebook.com/moblanc.art/>. Acesso em: maio, 2020. 


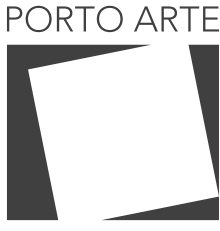

Revista de Artes Visuais

v. 25 ก. 43

Jan/jun 2020 e-ISSN: 2179-8001

àqueles que não visitaram a exposição. Os vídeos foram disponibilizados no YouTube $^{4}$ e por meio das redes sociais do do Facebook ${ }^{5}$ e Instagram ${ }^{6}$, que são as plataformas sociais virtuais de maior acesso atualmente e contribuem para a divulgação e aproximação do público com as mostras.

Assim, visando movimentar o circuito cultural da cidade, atender colecionadores e investidores em arte, locais e regionais, e auxiliar novos colecionadores, ocorreu a exposição "Colecionismo". E, nesse sentido, a mostra apresentou uma diversidade de obras, em parceria com outras galerias - em uma dinâmica contemporânea de mercado -, que podem se adequar a distintas coleções e diferentes mercados.

A prática do colecionismo de arte contemporânea no Brasil é conduzida de forma discrepante em vários aspectos, como critérios muito bem articulados e gerenciamento que faz coexistirem processos em avançado estado de catalogação, conservação, legalização fiscal e sistema de empréstimos definidos, com outros de pouca ou nenhuma noção sobre tais aspectos. No entanto, pode-se afirmar que o papel social do colecionador tem avançado ao ponto de se pensar que o conceito de colecionismo de arte não pode, de fato nunca deveria ter sido, estar aprisionado em questões quantitativas que privilegiam número de obras, autoria e valores de mercado. A figura de quem coleciona tem sido a de quem atua socialmente por meio da coleção, fazendo dela um elemento disparador de agenciamentos sociais capazes de contribuir com o desenvolvimento do sistema das artes visuais. (ROSA, 2020, p. 107).

Colecionar arte é poder contar histórias, é fazer vibrar memórias possíveis. Os caminhos para dar início a uma coleção de arte são diversos, seja a partir de uma obra específica, ou artista, ou período/local, bem como temáticas, vanguardas, regionalizações, correntes artísticas, linguagens, entre outros. Os "[...] colecionadores são agentes que adquirem ou adquiriram obras de artes por um período; coleção é um conjunto de objetos em desenvolvimento permanente, independente do aumento de número de obras" (ROSA, 2020, p. 100).

Entre o moderno e o contemporâneo, negligenciou-se, na exposição "Colecionismo", propositalmente, a ordem cronológica. A curadoria selecionou obras ${ }^{7}$ desde o pós-impressionismo de Henri de Toulouse-Lautrec até a fase neoclássica de Pablo Picasso e o surrealismo de Salvador Dalí. Na ausência de uma cronologia, buscou-se aguçar os sentidos mediante o olhar, sem se prender ao tempo, apenas às emoções que, porventura, os artistas permitiram provocar nos visitantes por

\footnotetext{
4- Disponível em: <https://www.youtube.com/watch?v=uemoA-BQ8Tc>. Acesso em: maio, 2020 5- Disponível em: <https://www.facebook.com/moblanc.art/>. Acesso em: maio, 2020. 6- Disponivel em: <https://www.instagram.com/moblanc.art/>. Acesso em: maio, 2020 7-Todas as obras são originais e acompanham certificados de autenticidade, ou, como no caso das litografias de Toulouse-Lautrec, chanceladas pelo Museu D'Albi.
} 


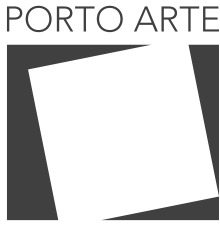

Revista de Artes Visuais v. 25 ก. 43 Jan/jun 2020 e-ISSN: 2179-8001

meio de artes, legado ou genialidade. A proposta curatorial foi revisitar a história da arte a partir de gatilhos: nomes de artistas expoentes, temáticas marcantes, vanguardas, artistas renomados, e permitir-se explorar o contemporâneo que reconhece e respeita a arte do passado e alcança, a partir dela, um lugar de destaque e de reconhecimento. De acordo com o texto curatorial,

\begin{abstract}
Um olhar peculiar sobre o passado, com projeções para o futuro, ou, fruto de uma paixão que visa bons investimentos. Há, também, no colecionismo o equilíbrio entre a sensibilidade e a razão, entre o desejo e a realização, bem como outras características possíveis. No intuito de sensibilizar seus convidados, a curadoria da exposição COLECIONISMO busca atrair os olhares para a Arte que conhecemos através dos livros, das viagens e passeios em museus e mostrar que sim, é possível colecionar arte, que o encantamento dessas peças pode acompanhar-nos no decorrer de nossas vidas, fazer parte da nossa história, das conquistas em família.
\end{abstract}

A questão atemporal é um dos conceitos da mostra, como sugere o final do texto de curadoria:

\footnotetext{
O tempo de COLECIONISMO é um só, é único, é uma fissura. Giorgio Agamben (2009) afirma que para ser contemporâneo é preciso ter coragem, e que para ver com clareza faz-se necessária a escuridão total. Caso fosse possível escurecer a sala expositiva, certamente haveria luz, na cisão de tempo que se pretende apresentar aqui, hoje. 0 tempo é o agora.
}

\title{
Curadoria e estratégias expositivas
}

A curadoria é um trabalho autoral e técnico que propõe gerar conceitos por meio das obras exibidas e dos diferentes aspectos que definem o contexto da exposição. 0 curador tem o papel de criar estratégias para proporcionar conhecimento e despertar curiosidades por meio da aproximação dos visitantes. Todas as exposições são passíveis de diversas interpretações, e compete ao curador, juntamente a uma equipe especializada, organizar a mostra da melhor maneira para que essa diversidade seja contemplada.

A exposição permite a visualização das obras numa narrativa estabelecida pelo curador, mas que se constrói também a partir do entendimento do público. Assim, o complexo sistema do modo expositivo é atribuído às intenções do curador e da instituição que recebe e/ou financia e, por vezes, à vontade do artista. De ordem técnica, a exposição, enquanto dispositivo estruturante da arte, requer experiência do curador e 


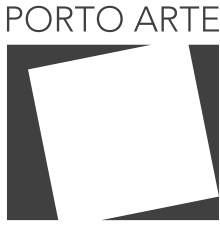

Revista de Artes Visuais

$\vee 25 n .43$ Jan/jun 2020 e-ISSN: 2179-8001

conhecimento específico da equipe de montagem e expografia. Por conseguinte, disponibiliza aspectos de ordem simbólica criativa, e entende-se a exposição enquanto narrativa, em que cada elemento presente colabora para a construção do todo.

Cabe ao curador observar de que maneira as informações chegam ao público, e para isso é possível lançar mão de estratégias que facilitam o entendimento, tais como textos de apresentação, folders, postagens em redes sociais, etiquetas contendo as fichas técnicas das obras, indicação de idade, se necessário, bem como orientar monitores e equipes de mediação, se houver.

Como diante de uma página em branco, no espaço de exposições, o curador não apenas define mas elabora o processo de montagem ativamente, junto a profissionais especializados como museólogos, arquitetos, designers, produtores, entre outros. 0 curador responde pela exposição, seu êxito, ou fracasso, por sua repercussão como um todo. Qualquer solução de mudança, substituição, corte, altura, distâncias, iluminação, etc., está sob a decisão e responsabilidade do curador. Entretanto, observa-se que essa é uma realidade que deve ser compartilhada por todos os envolvidos no processo de uma exposição (de produtores a artistas) (CASTILLO, 2015, p.67).

Ainda tratando das funções e práticas atribuídas à curadoria, conforme Ana Maria Albani de Carvalho:

A curadoria, por sua vez, assim como a crítica, é uma prática que se assenta em critérios, os quais justificam escolhas e exclusões. A especificidade das práticas curatoriais, quando consideramos a exposição, está - entre outros aspectos - em sua dimensão espacial e vivencial ou fenomenológica. (CARVALHO, 2013, p. 268-269).

Nota-se, contudo, que o ato de curar uma exposição diz respeito não somente à concepção e ao desenvolvimento, mas também aos momentos que sucedem à conclusão da montagem da mostra, incluindo os preparativos para a inauguração e a intenção de bem receber o visitante, estimulando-o à visitação. Não há uma receita, um método a ser seguido, para exercer curadoria de exposição de arte, sobretudo de arte contemporânea, em que (quase) tudo é possível.

Entretanto, são necessários criatividade, inventividade e olhar reflexivo para relacionar a arte às questões do cotidiano ou que se pretendem discutir, ou lançar luz sobre elas, de acordo com as dinâmicas propiciadas pelo espaço expositivo. Como já citado anteriormente, a "Colecionismo", por exemplo, foi curada para uma galeria de arte com foco no atendimento ao cliente, colecionador e investidor, sem desconsiderar os visitantes espontâneos. 


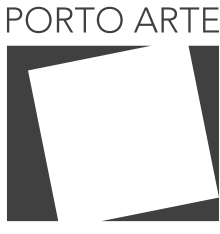

Revista de Artes Visuais

$\vee 25 n .43$

Jan/jun 2020 e-ISSN: 2179-8001

\section{Conceitos expográficos}

A Expografia denomina a área de pesquisa sobre as técnicas para concepção, organização e manutenção dos espaços expositivos. 0 processo de elaboração da exposição abrange o planejamento de estruturas como iluminação, suportes, sinalização, utilização de tecnologias e comunicação visual. Para Lisbeth Rebollo Gonçalves (2004), esse delineamento tem papel fundamental na comunicação do discurso e na condução da mensagem, portanto se trata de um importante recurso na construção da experiência do público.

O projeto expográfico tem como objetivo, portanto, delimitar o conteúdo da mostra. Geralmente isso acontece a partir do agrupamento e das relações de semelhanças ou diferenças, visuais e/ou conceituais, apresentadas pelas obras. Assim, a curadoria determina o tema e seleciona as obras, e, por conseguinte, a expografia organiza as produções no espaço físico, a partir de um determinado critério para agrupamento e distribuição.

0 espaço arquitetônico da galeria é próximo do conceito do cubo branco. As reflexões e críticas em torno da teoria do "Cubo Branco", por exemplo, originaram questões sobre a necessidade de espaços expositivos mais abrangentes e de modelos diferenciados de exposição. 0 modelo de local neutro, ideal para receber e apresentar diferentes produções artísticas, ainda é comumente utilizado, porém não atende às necessidades de exibição de algumas produções atuais. Conforme Brian O'Doherty (2002), o conceito do cubo branco inclui um ambiente artificial, branco, limpo, neutro do chão ao teto, com elementos como iluminação e ventilação dispostos de maneira discreta, para que toda e qualquer experiência alheia à estética expositiva fosse ignorada.

\footnotetext{
Não é sem motivo que o espaço expositivo passou a ter uma necessidade quase infinita de oferecer possibilidades de transformação espacial. E, paradoxalmente, também não é sem motivo que, por vezes o cubo branco se torna a melhor solução, assim como, em outras, revela-se como uma total inadequação. (CASTILLO, 2008, p. 310).
}

Nesse sentido, ao pensar o espaço interno da galeria $\left(80 \mathrm{~m}^{2} \times 16 \mathrm{~m}^{2}\right)$, procurou-se adaptar o mobiliário para produzir diferentes percursos e desenhos expositivos. 0 espaço conta, para isso, com quatro painéis e dois cubos móveis, com rodízios, em madeira branca. Neles, é possível dispor as obras de diversas maneiras, e também servem como espaços de armazenamento, pois possuem compartimentos internos, projetados para a armazenagem do acervo. As paredes e o teto são brancos, a iluminação é em led, embutida no gesso, e os trilhos, com spots direcionáveis e ajustes de foco, advêm exclusivamente do teto, com pé direito de aproximadamente 5 metros.

De acordo com o espaço físico descrito anteriormente, pensou-se no percurso do visitante convergindo com a sequência de obras a serem disponibilizadas no espaço expositivo: inicialmente, as obras do mercado secundário (em parceria com a Galeria Duque), e, posteriormente, as obras do mercado primário (artistas representados pela galeria e pelo Escritório de Arte), ou seja, do moderno ao contemporâneo. 


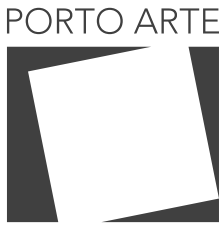

Revista de Artes Visuais

V.25 ก. 43 Jan/jun 2020 e-ISSN: 2179-8001

Figura 2 - Expografia da instalação In_corpórea, da artista Carolina Berger, junto à escultura Erosfágica, de Catiuscia Dotto. Fonte: Acervo particular.

Figura 3 - Espaço do colecionador e texto adesivado. Fonte: Acervo particular

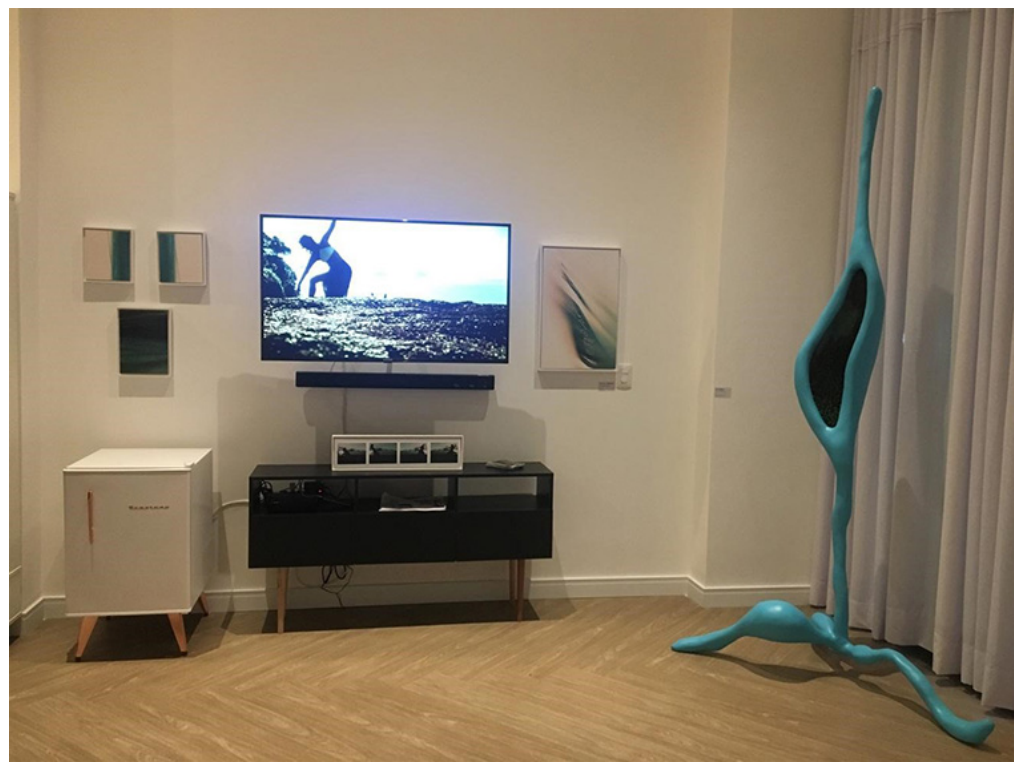

No espaço destinado às obras do mercado primário, iniciou-se o projeto expográfico a partir da obra de Carolina Berger, pois tratava-se de uma instalação com videoperformance, que foi veiculado no aparelho de televisão fixado em uma parede (Figura 2). As obras de arte contemporâneas foram integradas ao mobiliário, e buscou-se firmar a ideia de que as diferentes linguagens podem ser adquiridas para compor os espaços residenciais dos clientes/visitantes e para integrar às suas coleções já existentes, ou dar início a uma nova coleção.

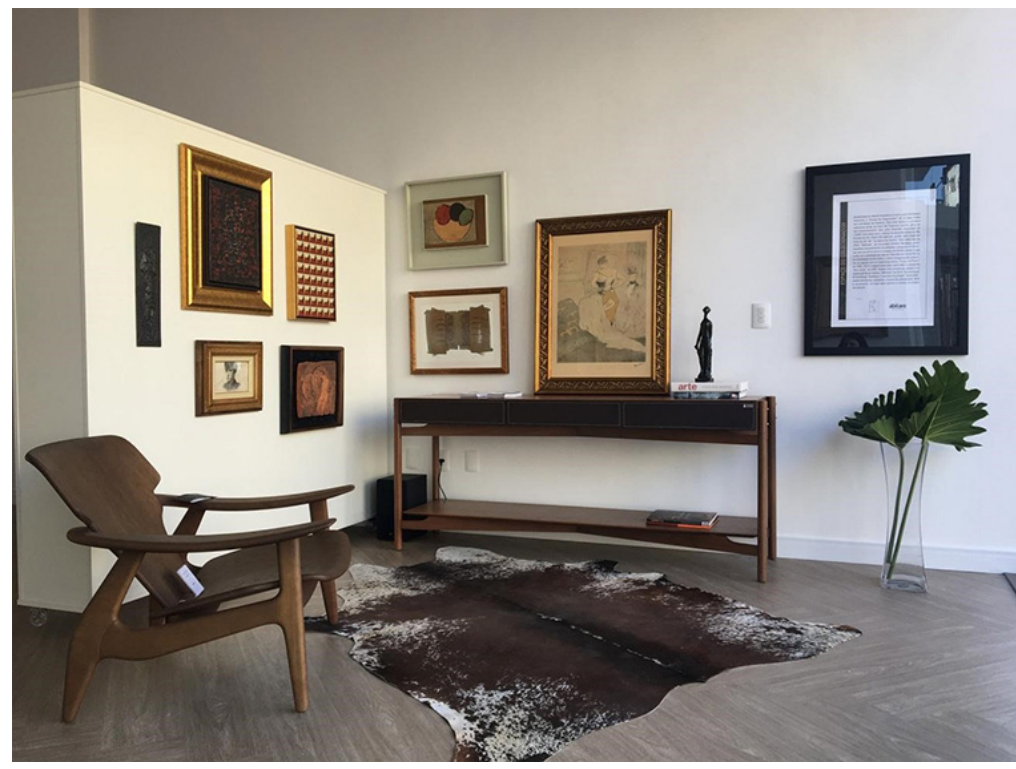




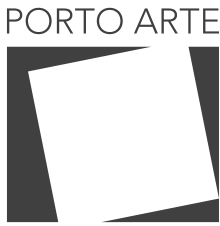

Revista de Artes Visuais

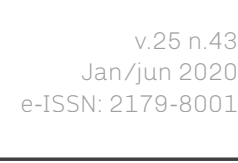

Figura 4 - Texto de curadoria adesivado em painel. Fonte: acervo particular
$\mathrm{Na}$ entrada da galeria, a fim de recepcionar o público, foi projetado o "Espaço do Colecionador". Ambientado em parceria com um escritório de arquitetura da cidade e uma loja de mobiliários, com o conceito de colecionismo, obras de arte e design foram dispostas conforme o texto ${ }^{8}$ também exposto ao público, adesivado na parede à direita do aparador (Figura 3).

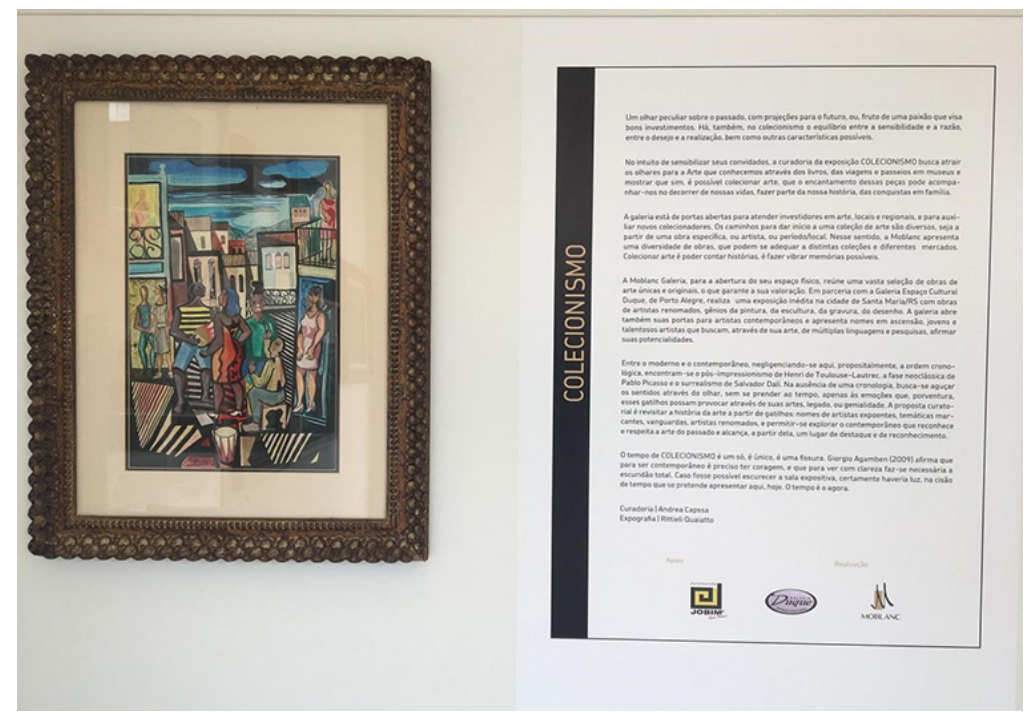

O texto de curadoria disponibilizado para auxiliar a fruição do público foi disposto em adesivo no painel logo na entrada da galeria, ao lado da obra Samba (1964), de Di Cavalcanti. Ele evidencia o conceito de colecionismo proposto, ao buscar incentivar o desejo por colecionar obras de arte ou estimular colecionadores na aquisição de novas peças (Figura 4).

A estrutura adotada para delimitar o espaço físico surge a partir de duas frentes: a produção moderna, advinda do acervo da Galeria Espaço Cultural Duque, e a produção contemporânea, dos artistas representados pela galeria e pelo Escritório de Arte de Porto Alegre. Ambas as produções coexistem no mesmo espaço, porém são delimitadas pelos painéis móveis.

Assim, ao entrar na exposição, o público foi surpreendido por obras de artistas consagrados, pinturas, esculturas, desenhos e gravuras. Ao percorrer até o final da mostra, encontrou produções mais atuais, com linguagens e técnicas diversas, como fotografia, videoperformance e realidade aumentada.

\footnotetext{
8- "Para este espaço a curadoria selecionou obras de Henri de Toulouse-Lautrec, gênio do pós-impressionismo, com uma litografia chancelada de c.1890. Uma peça rara e valiosa do expoente artista do Rio Grande do Sul, Pedro Weingärtner: grafite sobre papel do início do séc. XX, La signorina Valeria. Óleo sobre tela de 1951. Abstrato, do renomado Antônio Bandeira, pintor brasileiro mundialmente reconhecido e presente em diversos acervos particulares e museais em âmbito global, e que evidencia a qualidade da coleção. Expoente da arte do Rio Grande do Sul, o gravador e escultor Vasco Prado enriquece o espaço com a sua obra Mulher e cavalo, em terracota. Nascidos em Santa Maria, os renomados Carlos Scliar e Carlos Vergara estão presentes na seleção com as respectivas obras: Frutas no Prato, de 1985, vinil e colagem encerados sobre tela e a serigrafia Sem título, de 1997. Abstrato de 2017, a peça mais recente dessa seleção, é de autoria de Paula Kadunc e evidencia a tendência geométrica da artista. Esculturas de Bruno Giorgi, Banhista I, e de Xico Stockinger, Guerreiro, ambas em bronze, compõem o espaço do colecionador. Este é, certamente, um lugar para admirar e constar na ordem dos desejos
} 


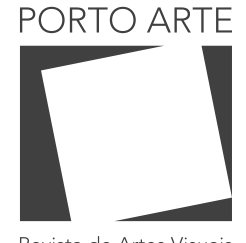

v. 25 n. 43 Jan/jun 2020 e-ISSN: 2179-8001
[...] a exposição é a interface na qual ocorre o confronto obra-espectador, por meio dela o artista propõe suas ideias, questiona inclusive a própria exposição, dialoga, e cria seu próprio contexto expositivo. A exposição torna-se espaço para diálogo, onde a teoria, a crítica e a história são elementos básicos para a discussão do conteúdo. A exposição é o espaço de troca de experiências, do diálogo, da discussão, da síntese. Enfim, a articulação dos elementos constituintes do sistema leva a concretização da exposição enquanto tal. (VÁLIO, 2008, p. 3).

Julgou-se que os visitantes reconheceriam mais facilmente as obras de artistas renomados e suas possíveis conexões a estudos, leituras e visitas aos museus, o que de fato aconteceu com algumas peças, como no caso da obra Palmeiras, de Tarsila do Amaral, serigrafia datada de 1972, assinada pela artista mundialmente conhecida, com a sua biografia, obras e trajetória presentes em livros de história da arte.

Curiosamente, essa obra foi uma das primeiras a serem vendidas. Acredita-se que o interesse do comprador se deu pelo potencial de investimento da obra, uma vez que, recentemente, a exposição de Tarsila do Amaral, em São Paulo, bateu recorde de visitações ${ }^{9}$. Entretanto, de acordo com o cliente, foi sua sensibilidade em relação à obra que fez com que ele a adquirisse.

\section{Considerações}

Cada vez mais especializadas e voltadas para o mercado, as galerias tornaram-se múltiplas, no sentido de não somente expor e comercializar, mas proporcionar conhecimento, facilitar o acesso e a disseminação da arte, e propor novas alternativas de atuação em rede ao usufruir das tecnologias possíveis e da internet.

Nesse sentido, no estudo aqui apresentado, referindo-se à exposição "Colecionismo", observa-se que o sistema em fluxo exige que as ações propostas e executadas pela curadoria estejam em consonância com os objetivos da galeria: gerar interesse do público para visitar a exposição e participar dos eventos promovidos por esse espaço , atrair colecionadores ou instituições públicas e privadas para possíveis investimentos e/ou parcerias, legitimar seus artistas e dar visibilidade aos acervos compartilhados. E, para que as ações em curso alcancem seus objetivos, conta-se com o papel fundamental do curador, uma vez que a curadoria assume, no sistema contemporâneo da arte, diversos papéis, sempre em busca da aproximação entre público e obra (GREFFE, 2013).

Vê-se, contudo, na contemporaneidade, um novo perfil de colecionadores. De acordo com Bruna Fetter, "[...] foi registrado um aumento do interesse dos colecionadores por maior conhecimento e 'uma vontade de aderir ao sistema', ao realizar suas compras através de galerias" (in: BULHÕES, 2014, p. 132), o que ratifica a compreensão sobre o sistema artístico e sobre os processos de legitimação e valorização da produ- 


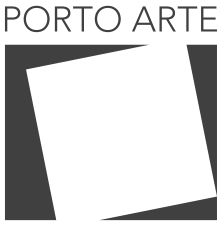

Revista de Artes Visuais

$\vee 25 n .43$

Jan/jun 2020 e-ISSN: 2179-8001

ção em arte. As galerias estão atentas à estética estratégica, da beleza e do espetáculo, da emoção e do entertainment para conquistar mercados.

O colecionador que faz circular suas obras no sistema, ao emprestar peças para exposições, produzir catálogos e promover eventos, torna-se uma "[...] personalidade cultural reconhecida e respeitada pela sociedade [...]" (MELO, 2012, p. 17). Observa-se que os colecionadores são pontos-chave no sistema da arte, uma vez que a possibilidade de fazer circular obras de arte no mercado secundário, ou seja, obras que retornam para o mercado, ocorre por meio deles, dos colecionadores proprietários dessas peças que, por algum motivo, optam pela revenda. É a mola propulsora do mercado secundário e figura cobiçada no mercado primário, pois o fato de um colecionador, reconhecido e legitimado pelo sistema, adquirir obra de um artista em plena atividade, contemporâneo, corrobora a legitimação do próprio artista, valorizando a sua obra e inserindo-a no sistema da arte.

Estar atento ao mercado e às possibilidades que surgem por meio dele depende também de um olhar empreendedor por parte dos agentes do campo da arte, sobretudo do curador, que, ao compreender as dinâmicas do sistema da arte, identifica possibilidades de exercer a curadoria também no âmbito do mercado, ao buscar obras e artistas para suprir a demanda, organizar exposições e propor eventos para assistir os colecionadores e investidores em arte.

No período de trinta dias em que esteve aberta ao público, a exposição "Colecionismo" contabilizou cerca de 350 visitações. Além das visitações gerais, foram recepcionados, de modo exclusivo, com agendamento, nove colecionadores. Foram realizadas em torno de 10 visitas guiadas para grupos de estudantes universitários dos cursos de Arquitetura, Artes Visuais e Música.

Durante o mês de visitação, foram reservadas 18 obras, das quais 13 foram vendidas e substituídas por obras dos mesmos artistas para manter a expografia e o fluxo da exposição, bem como os conceitos curatoriais. Também foram realizadas encomendas de obras sob medida, de artista contemporâneo, para compor uma série de 4 obras para empreendimento em Santa Maria/RS e 1 obra para empreendimento em Gramado/RS.

Por meio das ações in loco e no meio virtual, as redes sociais da galeria dobraram o número de seguidores, aumentando consideravelmente o índice de compartilhamento dos conteúdos, dos comentários, curtidas, menções e também do recebimento de dúvidas sobre as obras no chat privado. Destacam-se, aqui, duas vendas efetuadas por meio do Instagram, a partir do interesse demonstrado nas enquetes disponibilizadas na mesma plataforma.

Considera-se que a partir dessa mostra e das ações propostas, foi possível atender às demandas dos colecionadores e fidelizar visitantes e clientes. 0 propósito de disseminar arte e fortalecer o sistema local foi atingido, e acredita-se que as estratégias implementadas corroboram as iniciativas das curadoras autoras do presente artigo. 


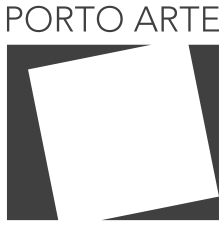

Revista de Artes Visuais

$\times 25 \times 43$ Jan/jun 2020 e-ISSN: 2179-8001

\section{REFERÊNCIAS}

AGAMBEN, Giorgio. O que é o contemporâneo? E outros ensaios. Chapecó: ARGOS, 2009.

ARCHER, Michael. Arte Contemporânea: uma história concisa. São Paulo, Martins Fontes, 2001.

BULHÕES, Maria Amélia. Artes plásticas: participação e distinção Brasil anos 60/70. Tese (doutorado - Faculdade de Filosofia, Letras e Ciências Humanas da USP). Universidade de São Paulo. São Paulo, 1990. Disponível em: <https://www. ufrgs.br/artereflexoes/site/2019/05/15/tese-de-doutorado-artes-plasticas-participacao-e-distincao-brasil-anos-60-70-de-maria-amelia-bulhoes/>. Acesso em: abr, 2020.

BULHÕES, Maria Amélia. Arte Contemporânea no Brasil. Belo Horizonte: C/Arte, 2019.

CARVALHO, Ana Maria Albani de. Curadoria e Potencialidade Crítica na Arte Pós-Autônoma. Anais do XXXIII COLÓQUIO DO COMITÊ BRASILEIRO DE HISTÓRIA DA ARTE - Arte e suas instituições, 2013, p. 257-270. Disponível em: <http://www. cbha.art.br/coloquios/2013/anais/pdfs/s2_anamariaalbani.pdf>. Acesso em: maio, 2020.

CASTILLO, Sonia Salcedo del. Cenário da arquitetura da arte: montagens e espaços de exposições. São Paulo: Martins, 2008.

CASTILLO, Sonia Salcedo del. Arte de expor: curadoria como expoesis, 2015.

FETTER, Bruna. Um bom negócio: as recentes movimentações do mercado de arte contemporânea no Brasil. in BULHÕES, Maria Amélia (org.). As novas regras do jogo: o sistema de arte no Brasil. Porto Alegre: Zouk, 2014.

FIALHO, Ana Letícia. O mercado de arte contemporânea no Brasil. Pesquisa Setorial Latitude. $3^{\text {a }}$ Edição, 2014.

GONÇALVES, Lisbeth Rebollo. Entre cenografias: o museu e a exposição de arte no século XX. São Paulo. EDUSP, 2004.

GREFFE, Xavier. Arte e Mercado. (Org. Teixeira Coelho) tradução Ana Goldberger. - ed.São Paulo. Iluminuras: Itaú Cultural, 2013.

LINDEMANN, Adam. Coleccionar Arte Contemporaneo. Colonia: Taschen, 2006.

MELO, Alexandre. Sistema da Arte Contemporânea. Lisboa: Europrees, 2012.

MOULIN, Raymonde. O Mercado da Arte: mundialização e novas tecnologias. Porto Alegre: Zouk, 2007.

O'DOHERTY, Brian. No interior do cubo branco: a ideologia do espaço da arte. São Paulo: Martins Fontes, 2002.

QUAIATTO, Rittieli D'Avila. Do Espaço Expositivo à Mediação em Arte e Tecnologia: estudo de caso do FACTORS. Dissertação (mestrado - Programa de Pós-Graduação em Artes Visuais). Universidade Federal de Santa Maria. Santa Maria 2019. Disponível em: <https://repositorio.ufsm.br/handle/1/19302>. Acesso em: out, 2020.

QUEMIN, Alain (Org.); FIALHO, Ana Letícia; MORAES, Angélica de. O valor da obra de arte. São Paulo: Metalivros, 2014.

ROSA, Nei Vargas da. O que é contemporâneo no colecionismo de arte contemporâ- 


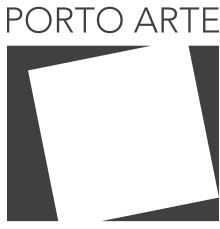

Revista de Artes Visuais

v. 25 n. 43 nea?. Revista Estado da Arte, Uberlândia. v.1, n.1, p. 97-109, jan./jun. 2020. [https://doi.org/10.14393/EdA-v1-n1-2020-55511]. Disponível em: <http://www. seer.ufu.br/index.php/revistaestadodaarte/article/view/55511/29899>. Acesso em: out, 2020.

SILVEIRA, Andrea Aparecida Capssa de Lima da. Considerações sobre as galerias virtuais e suas relações com o mercado de arte. Dissertação (mestrado - Programa de Pós-Graduação em Artes Visuais). Universidade Federal de Santa Maria. Santa Maria, 2016. Disponível em: <https://repositorio.ufsm.br/handle/1/5244>. Acesso em: out, 2020.

VÁLIO, Luciana Benetti Marques. Mapeando a complexidade da exposição de arte: é possível avalia-la?. São Paulo, 2008. Dissertação (Mestrado em Ciência da Informação) - Escola de Comunicações e Artes, Universidade de São Paulo. 


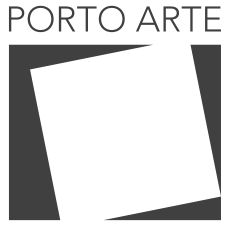

Revista de Artes Visuais

V.25 n. 43

Jan/jun 2020 e-ISSN: 2179-8001

Texto submetido em: $30 / 05 / 2020$

Texto aprovado em: 19/06/2020

Texto publicado em: $30 / 06 / 2020$

\section{Rittieli D'Avila Quaiatto}

Mestre em Artes Visuais PPGART/UFSM. Especialista em Design de Superfície/ UFSM. Bacharel em Artes Visuais/UFSM. Integrante do LABART e Grupo de Pesquisa Arte e Tecnologia/CNPq (2016-), com bolsa de mestrado CAPES. Curadora Assistente da MOBLANC Galeria de Arte.

\section{Andrea Capssa de Lima}

Doutoranda em Artes Visuais PPGART/UFSM (2019 -). Mestre em Artes PPGART/ UFSM. Bacharel em Artes Visuais/UFSM. Integrante do LABART e Grupo de Pesquisa Arte e Tecnologia/CNPq (2011-), com bolsa IC FIEX e bolsa mestrado e doutorado CAPES. Diretora e Curadora da MOBLANC Galeria de Arte. 